\title{
METODE PENGEMBANGAN PRODUK QFD UNTUK MENINGKATKAN DAYA SAING PERUSAHAAN
}

\author{
Dyah Lintang Trenggonowati \\ Teknik Industri Fakultas Teknik, Universitas Sultan Ageng Tirtayasa, Cilegon, Indonesia \\ dylintre@gmail.com ; dyahlintang@untirta.ac.id
}

\begin{abstract}
Abstrak
Metode QFD bagi perusahaan yang berusaha meningkatkan daya saingnya melalui perbaikan kualitas dan produktifitasnya secara berkesinambungan adalah meningkatkan keandalan produk, meningkatkan kualitas produk, meningkatkan kepuasan konsumen, memperpendek time to market, mereduksi biaya perancangan, meningkatkan komunikasi, meningkatkan produktivitas dan meningkatkan keuntungan perusahaan. Disamping itu QFD juga bertujuan untuk pengembangan produk yang dapat memuaskan konsumen dengan menterjemahkan keinginan konsumen ke dalam karakteristik teknis yang menjadi sasaran desain dan elemen pengendalian mutu untuk digunakan di seluruh proses produksi. Kemampuan menghasilkan produk sesuai dengan kebutuhan dan keinginan konsumen merupakan faktor kunci yang harus dimiliki oleh perusahaan untuk dapat menghasilkan produk yang berdaya saing tinggi.

Metode pengembangan produk QFD telah banyak diterapkan di bidang industri untuk memaksimalkan kepuasan pelanggan dengan berbasis pada perbaikan kualitas, dan lainnya, dan semuanya kembali sebagai sumber kendala. Perbaikan kualitas adalah faktor penting untuk sebuah perusahaan agar dapat mempertahankan keeksistensian perusahaannya di dunia industri. Di beberapa penelitian sebelumnya lebih banyak fokus pada faktor perbaikan kualitas yaitu bagaimana membantu perusahaan untuk mendapat kepuasaan dari konsumen, sedangkan faktor bagaimana agar perusahaan mampu meningkatkan daya saing kurang mendapat perhatian, kalaupun ada tidak dihitung dan dibahas secara detil.
\end{abstract}

Kata kunci: Daya Saing, Perbaikan Kualitas, QFD

\section{PENDAHULUAN}

Hampir tidak pernah ada perusahaan yang dapat menghindar dari adanya pengaruh kemajuan teknologi dan munculnya produk-produk baru. Cepat atau lambat, hampir semua produk yang ada saat ini akan hilang dari pasar dan digantikan dengan produk-produk lain yang baru sehingga pertumbuhan dan keuntungan perusahaan dalam jangka panjang akan tergantung dari kebijaksanaan produk yang didefinisikannya. Dalam kondisi saat ini, dimana perkembangan pasar sangat dinamis dan penuh persaingan, perusahaan akan sulit untuk mempertahankan eksistensinya jika hanya bertahan pada produknya yang sekarang. Oleh karena itu, pengembangan produk baru merupakan suatu hal yang penting bagi perusahaan. Pengembangan produk baru tersebut meliputi pembuatan produk yang baru atau penyempurnaan dari produk yang sudah ada (Kotler, 2002).

Menangkap hal tersebut, tujuan dari prinsip QFD adalah untuk memastikan bahwa kebutuhan dan keinginan pelanggan dapat terpenuhi dalam proses penurunan suatu produk. Karena itulah dikatakan mengapa QFD bermula dari suara pelanggan $(\mathrm{VOC}=$ voice of customer) dan sering dalam bahasa Inggris QFD disebut sebagal customer-driven product development atau customer-fucosed design. Sasaran pertama dari QFD adalah selalu menghindari marketing misses produk jatuh dipasarkan akibat kalah bersaing. Sasaran kedua QFD adalah untuk meningkatkan laju dan effisiensi dan proses pengembangan produk.

Beberapa penelitian sebelumnya misalnya, "Mengembangkan fungsi kualitas dengan pendekatan (E-QFD) dari perencanaan produk ke part deployment. Metode clustering diusulkan untuk mengklasifikasikan berbagai hambatan (atau kepentingan) kelompok part characteristics ke part deployment" (Zhai et al., 2009). "Pendekatan optimasi QFD yang dikombinasikan dengan model MILP (Mix Integer Linear Programming) dan model Kano untuk memperoleh maximize customer satisfaction" (Kilic dan Gungor, 2009). "Pendekatan QFD digunakan sebagai perangkat transformasi untuk menghubungkan faktor kompetitif 
dengan manufaktur. Dimana keputusan kategori keputusan struktural dan kategori infrastruktur menggunakan pendekatan QFD yang diintegrasikan dengan fuzzy sebagai alat utama dalam berbagai tahap proses strategi manufaktur" (Jia dan Bai, 2010). "Membandingkan antara metodologi yang diusulkan dan fuzzy QFD tradisional, selain itu metodologi yang diusulkan mampu sebagai decision making atas suara konsumen dan teknologi yang belum jelas untuk memperoleh maximize customer satisfaction" (Zhai et al., 2010). "Menentukan sumber daya kunci proses dengan estimasi biaya manufaktur dengan pendekatan $\mathrm{ABC}$, memilih proses alternatif dengan pendekatan FMEA dan meningkatkan kualitas proses manufaktur dengan pendekatan QFD" (Hassan et al., 2010). "Sebuah pengembangan produk baru dengan proses empat fase QFD dalam mencapai tingkat pemenuhan design reqirements, part requirements, part characteristics, dan production requirements dengan menggunakan fuzzy method" (Chen dan Ko, 2009).

Pada saat ini, kenyataannya manfaat QFD bagi perusahaan yang berusaha meningkatkan daya saingnya melalui perbaikan kualitas dan produktifitasnya secara berkesinambungan adalah dengan meningkatkan keandalan produk, meningkatkan kualitas produk, meningkatkan kepuasan konsumen, memperpendek time to market, mereduksi biaya perancangan, meningkatkan komunikasi, meningkatkan produktivitas dan meningkatkan keuntungan perusahaan (Cohen, 1995).

Dari permasalahan seperti yang diuraikan di atas maka dikembangkan suatu konsep baru bagaimana merespon permintaan pelanggan yang baik yaitu dengan mengintegrasi semua faktor yang ada yang biasa disebut dengan QFD 4 fase sehinggga diharapkan mampu meningkatkan daya saing perusahaan.

\section{LANDASAN TEORI}

Agar pelaksanaan pengembangan produk dapat berjalan dengan baik dan sesuai dengan yang diharapkan, perlu diperhatikan tahap-tahap dalam melaksanakan pengembangan produk. Menurut Kotler (2002), tahap-tahap pengembangan produk terbagi menjadi delapan tahap yaitu :

1. Pemunculan Gagasan

Pengembangan produk berawal dari pencarian gagasan. Gagasan produk biasanya berasal dari berbagai sumber, diantaranya yaitu manajer pengembangan dan penelitian, pelanggan, ilmuwan, pesaing, pegawai, pesaing, saluran pemasaran dan manajemen puncak

2. Penyaringan Gagasan

Gagasan yang disampaikan oleh pihak-pihak di atas disortir menjadi tiga kelompok yaitu gagasan yang menjanjikan, gagasan yang pas-pasan, dan gagasan yang ditolak. Dalam menyaring gagasan, perusahaan harus memperhatikan dan menghindari dua kesalahan yaitu

a. Kesalahan Membuang, kesalahan ini terjadi jika perusahaan membuang ide yang sebenarnya baik untuk dikembangkan. Karena kurangnya gambaran perusahaan terhadap potensi ide tersebut maka perusahaan membuangnya

b. Kesalahan Jalan Terus, kesalahan ini terjadi apabila perusahaan mengembangkan ide yang sebenarnya merugikan, hal ini akan mengakibatkan produk yang dikembangkan mengalami kegagalan di pasar

3. Pengembangan dan Penyajian Konsep

Gagasan yang menarik harus disempurnakan menjadi konsep yang dapat diuji, gagasan produk adalah yang mungkin dapat ditawarkan oleh perusahaan ke pasar. Konsep produk adalah versi terinci dari suatu gagasan yang dinyatakan dalam istilah-istilah yang berarti bagi konsumen

4. Pengembangan Strategi Pemasaran

Perusahaan yang mengembangkan produk dengan melalui strategi pemasarannya perlu memperkenalkan produknya kepada pasar, yang mencakup tiga bagian pokok yaitu 
a. Bagian pertama

- Menjelaskan ukuran, struktur dan perilaku pasar sasaran

- Rencana penentuan posisi produk, penjualan, pangsa pasar dan laba yang diinginkan dalam beberapa tahun yang akan datang

b. Bagian kedua

- Mengikhtisarkan rencana harga produk itu

- Strategi distribusi

- Anggaran pemasaran untuk tahun pertama

c. Bagian ketiga

- Menjelaskan penjualan jangka panjang

- Menjelaskan sasaran laba

- Menjelaskan strategi bauran pemasaran selama jangka waktu itu

5. Analisis Bisnis

Setelah manajemen mengembangkan konsep produk dan strategi penasaran, manajemen dapat mengevaluasi daya tarik bisnis. Manejemen perlu melakukan persiapan proyeksi penjualan, biaya, dan laba untuk menentukan apakah semua itu memenuhi tujuan perusahaan. Jika memenuhi, konsep itu dapat dilanjutkan ketahap pengembangan produk

6. Pengembangan Produk

Jika konsep produk dapat melewati pengujian bisnis, konsep itu akan berlanjut ke bagian litbang dan/atau rekayasa untuk dikembangkan menjadi produk fisik

7. Pengujian Pasar

Tahap dimana produk diberi merk, kemasan dan program atas tanggapan konsumen dan penyaluran terhadap masalah-masalah perlakuan, penggunaan dan pembelian barang ulang produk senyatanya serta pengkajian atas seberapa luas pasar sesungguhnya. Luasnya pengujian pasar yang harus diadakan akan bergantung pada dua segi yaitu biaya dan risiko penanaman modal disatu pihak dan pihak lainnya adalah keterbatasan waktu dan biaya penelitian.

8. Tahap Komersialisasi

Tahap ini merupakan tahap peluncuran produk ke pasar dimana perusahaan yang berkapasitas sebagai produsen suatu produk akan memutuskan mengenai peluncuran produk ke pasar. Dalam tahap ini, kewajiban manajemen adalah menentukan kapan (when), kepada siapa (who), dan bagaimana (how) produk-produk itu dipasarkan

\section{House of Quality (HOQ)}

The house of quality adalah suatu kerangka kerja atas pendekatan dalam mendesain manajemen yang dikenal sebagai Quality Function Deployment (QFD) (Cohen, 1995).

The House of Quality memperlihatkan struktur untuk mendesain dan membentuk suatu siklus, dan bentuknya menyerupai sebuah rumah. Kunci dalam membangun HOQ adalah difokuskan kepada kebutuhan pelanggan, sehingga proses desain dan pengembangannya lebih sesuai dengan apa yang diinginkan oleh pelanggan daripada teknologi inovasi. Hal ini dimaksudkan untuk mendapatkan informasi yang lebih penting dari pelanggan.

Hal tersebut mungkin menambah waktu perencanaan awal (initial planning time) dalam proyek pengembangan, tetapi waktu desain atau me-redesain dan membawa produk atau jasa kepasaran (time to market) akan berkurang.

HOQ merupakan suatu organisasi dalam arti inter-departemental atau inter-junction planning \& communication yang berawal dari atribut-atribut pelanggan (Customer Atributes/Cas) yang menggambarkan produk, proses, dan karakteristik. Gambar 1 yang menunjukan komponen-komponen penting dari tabel kualitas atau diagram QFD-The House of Quality. 


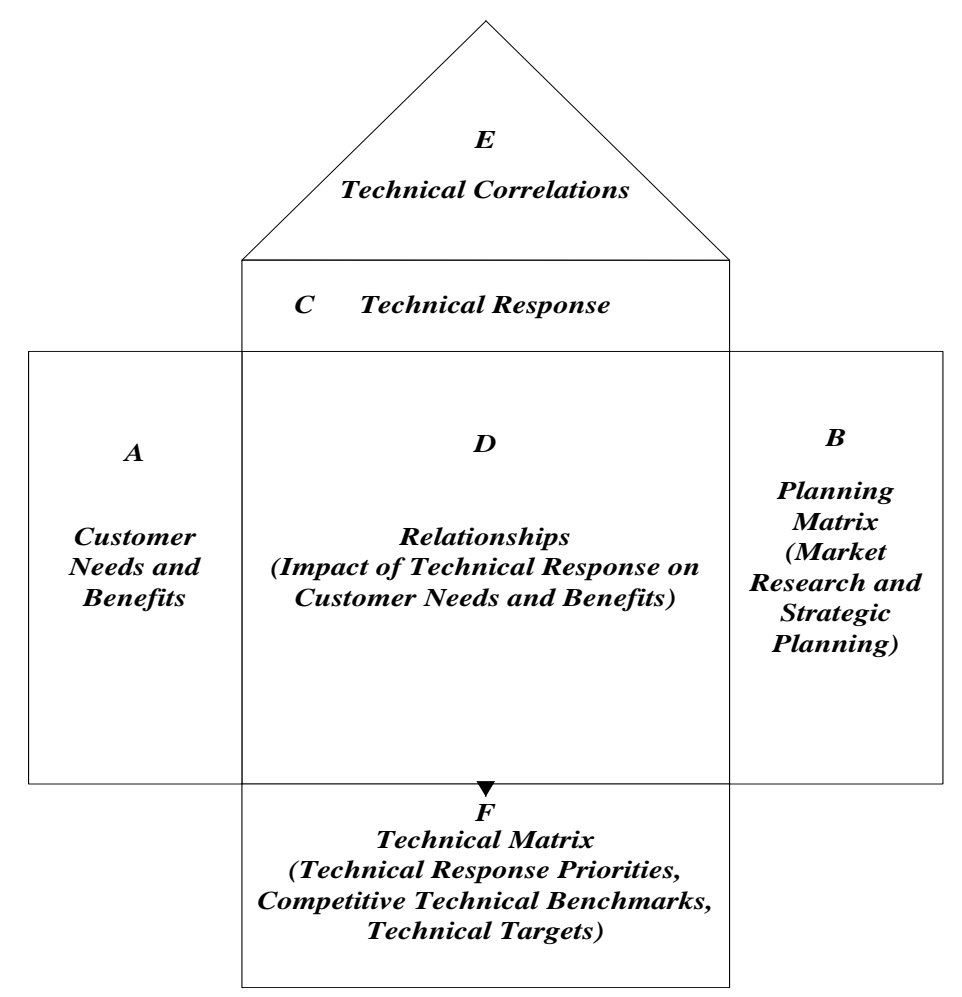

Gambar 1. House of Quality (Sumber: Cohen, 1995)

\section{Konsep kepuasan konsumen berdasarkan model Kano}

Setiap produk akan terdiri dari beberapa atribut kualitas yang bertujuan untuk memenuhi kebutuhan konsumen. Namun, pada dasarnya tidak semua atribut kualitas yang melekat dalam sebuah produk merupakan atribut-atribut kualitas yang mampu meningkatkan kepuasan konsumen dan sebaliknya tidak semua atribut ini dianggap penting oleh konsumen. Ada sebuah hubungan non-linear antara performance atribut kualitas dengan tingkat kepuasan konsumen. Dengan demikian, salah satu hal penting yang harus dipahami adalah impact masing - masing atribut kualitas yang ada pada produk terhadap peningkatan kepuasan konsumen yang menggunakannnya.

Konsep Kano yang diringkas dari Sauerwein (1996), Matzler dan Hinterhuber (1998), Walden (1999), Xu et al (2009), dan Garibay et al (2010) adalah membagi macammacam atribut kedalam beberapa kategori yaitu:

1) Must-be (basic needs), yaitu suatu requirement yang harus ada dalam sebuah produk serta dapat dikatakan pula sebagai minimum requirement (12Manage, The Excecutive Fast Track, 2011). Requirement ini merupakan atribut utama yang akan diperhatikan oleh konsumen dan merupakan fungsi utama dari produk. Konsumen akan sangat tidak puas apabila requirement ini tidak ada. Pada dasarnya, kategori requirement ini tidak dapat meningkatkan kepuasan konsumen, hanya saja berperan penting untuk menjaga agar konsumen tidak kecewa terhadap produk yang ditampilkan. Walaupun sebenarnya, kategori must-be tidak dapat meningkatkan kepuasan konsumen, namun kategori ini menjadi faktor kritis dimana faktor tersebut akan berpengaruh pada keputusan pembelian.

2) One-dimensional (performance), merupakan suatu atribut kualitas yang mana ketika dimunculkan dalam sebuah produk, konsumen akan merasa puas dan sebaliknya akan menyebabkan ketidakpuasan pada konsumen apabila requirement ini tidak dipenuhi. Semakin tinggi performance ini maka akan semakin tinggi pula tingkat kepuasan konsumen yang dengan kata lain hubungannya linear. 
3) Attractive (excitement factor), ketidakhadiran requirement ini tidak akan menimbulkan kekecewaan pada konsumen karena bukan merupakan harapan utama konsumen dalam membeli produk. Namun, ketika requirement ini ada dalam sebuah produk sudah tentu akan membuat konsumen merasa senang. Kategori ini termasuk dalam requirement yang diekspresikan secara eksplisit oleh konsumen.

4) Indifference factor, merupakan salah satu kategori atribut produk yang mana ada tidaknya atribut tersebut dalam sebuah produk sama sekali tidak akan perpengaruh pada tingkat kepuasan konsumen

5) Reserve factor, merupakan atribut produk yang apabila dimunculkan hanya akan berpengaruh pada penurunan tingkat kepuasan konsumen (Wang et al, 2008).

Gambar 2 merupakan gambar yang menunjukkan posisi dan pergerakan masing-masing kategori klasifikasi model Kano yang mana memiliki karakteristik hubungan dengan tingkat kepuasan konsumen yang berbeda-beda. One-dimensional factor berpengaruh pada tingkat kepuasan konsumen dengan hubungan yang linear dengan nilai kemiringan yang tetap. Berbeda dengan faktor one-dimensional, faktor attractive dan must-be memiliki hubungan yang nonlinear. Must-be factor memiliki kecenderungan menurun, kemiringan kurva dimulai dari tingkat kepuasan yang paling rendah akibat kegagalan fungsi atribut ini kemudian akan bertahap mendekati garis nol tingkat kepuasan konsumen (Lin et al, 2010). Hal ini berarti bahwa pada suatu titik tertentu, sebesar apapun nilai atribut must-be yang akan dikembangkan, usaha yang dilakukan tidak akan menjadi penting dan mendongkrak tingkat kepuasan konsumen. Attractive factor bergerak dengan kecenderungan meningkat mulai dari tidak adanya atribut ini dalam produk dan bertahap meningkatkan kepuasan konsumen. Ketika atribut ini muncul dalam sebuuah produk, akan berakibat pada peningkatan kepuasan konsumen (Matzler and Hinterhuber, 1998).

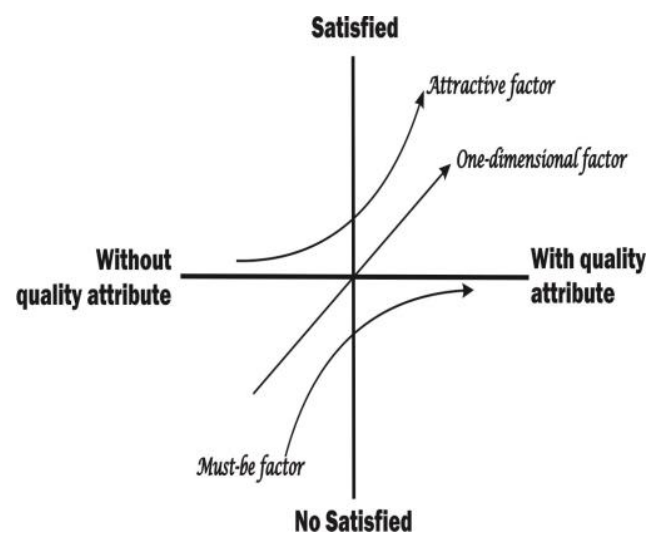

Gambar 2. Model Kano (Sumber: Garibay et al, 2010; Lin et al 2010)

\section{Keuntungan aplikasi model Kano dalam pengembangan produk}

Pada dasarnya, teori kano akan memberikan pemahaman yang lebih pada tim pengembang tentang gambaran produk yang diinginkan oleh konsumen. Namun dilain pihak teori ini sama sekali tidak dapat memberikan fasilitas pengambilan keputusan konsep produk seperti apa yang akan dilakukan proses lebih lanjut.

Keuntungan digunakannya model Kano untuk klasifikasi keinginan konsumen, menurut Matzler dan Hinterhuber (1998) adalah sebagai berikut :

1) Tim pengembang (perusahaan) akan lebih mengerti tentang apa yang diinginkan oleh konsumen dan akan lebih fokus terhadap kriteria-kriteria kualitas yang sudah terklasifikasi dalam must-be, one-dimensional dan attractive. Hal ini sangat penting mengingat kriteria kualitas produk sangat dipengaruhi oleh ketepatan dalam melakukan identifikasi kepuasan konsumen. 
2) Dapat membantu tim pengembang ketika terjadi trade-off antara faktor technical (produksi) dan financial sehingga dapat memilih kriteria yang paling berpengaruh pada tingkat kepuasan konsumen.

3) Klasifikasi must-be, one-dimensional dan attractive pada kriteria kualitas produk akan berbeda pada tiap segmen pasar sehingga dapat mengoptimalkan kepuasan konsumen untuk masing-masing segmen.

4) Attractive attribute dapat membantu tim pengembang untuk dapat membuat diferensiasi produk sehingga dapat menjadi daya tarik tersendiri bagi konsumen.

5) Model Kano dapat dikombinasikan dengan QFD (Quality Fuction Deployment). Model Kano ini dapat digunakan untuk menentukan tingkat kepentingan fitur produk untuk meningkatkan kepuasan konsumen dan sekaligus dapat mengoptimalkan proses QFD yang dilakukan.

\section{Aplikasi Model Kano}

Aplikasi model Kano dalam menganalisis keinginan kosumen menurut Lee (2008), Xu et al. (2009) dan Matzler et al. (1996) dapat dilakukan dengan menggunakan tahapan dan cara-cara berikut ini :

1. Penyusunan kuisioner

Kuisioner dibuat dengan menggunakan dua tipe pertanyaan yang saling berpasangpasangan dimana pertanyaan yang satu merupakan kebalikan dari pertanyaan yang lain. Kuisioner Kano akan terdiri dari pertanyaan yang saling berlawanan yaitu functional question dan dysfunctional question. Kedua jenis pertanyaan ini memiliki struktur kalimat yang sama, hanya saja functional question merupakan pertanyaan yang menyatakan kondisi apabila dalam sebuah produk ditampilkan permintaan konsumen " $\mathrm{x}$ ". Sedangkan dysfunctional question merupakan pertanyaan tandingan yang mana akan menyatakan kondisi dimana permintaan konsumen " $x$ " tersebut tidak ditampilkan dalam produk. Kedua tipe pertanyaan ini bertujuan untuk mengetahui tanggapan atau impact konsumen terhadap suatu requirement pada dua kondisi yaitu ditampilkan dalam produk atau tidak.

Dalam kuisioner ini, tiap pertanyaan akan terdiri dari 5 pilihan jawaban yang berbeda yaitu :

1. Sangat suka

2. Memang seharusnya ada

3. Netral

4. Tidak masalah

5. Tidak suka

2. Pengujian kuisioner

Pengujian kuisioner ini dilakukan sebelum kuisioner disebarkan ke responseen. Hal ini dilakukan untuk memastikan bahwa kuisioner yang disusun dapat dimengerti oleh responseen yang ditargetkan. Apalagi kuisioner Kano ini bukan kuisioner yang biasa digunakan oleh kebanyakan orang. Pengujian yang dilakukan berupa identifikasi struktur kalimat dan pemilihan kata untuk menghindari terjadinya kesalahan interpretasi dan kebingungan pada responseen. Pengujian ini dapat dilakukan dengan melakukan simulasi pada beberapa orang atau meminta pendapat expert.

3. Pengolahan Data

Pengolahan data kuisioner ini dilakukan untuk masing-masing pertanyaan dengan menggunakan matrix Kano sehingga dapat mengelompokkan atribut-atribut sesuai dengan kategori Kano. Berikut adalah matrix Kano yang dimaksud. 


\begin{tabular}{|c|c|c|c|c|c|c|c|}
\hline \multicolumn{2}{|c|}{ Customer Requirements } & \multicolumn{6}{|c|}{ Dysfunctional } \\
\cline { 4 - 8 } & $\mathbf{1}$ & $\mathbf{2}$ & $\mathbf{3}$ & $\mathbf{4}$ & $\mathbf{5}$ \\
\cline { 3 - 8 } & Like & Must-be & Neutral & Live with & Dislike \\
\hline \multirow{4}{*}{ Functional } & $\mathbf{1}$ & Like & $\mathrm{Q}$ & $\mathrm{A}$ & $\mathrm{A}$ & $\mathrm{A}$ & $\mathrm{O}$ \\
\cline { 2 - 8 } & $\mathbf{2}$ & Must-be & $\mathrm{R}$ & $\mathrm{I}$ & $\mathrm{I}$ & $\mathrm{I}$ & $\mathrm{M}$ \\
\cline { 2 - 8 } & $\mathbf{3}$ & Neutral & $\mathrm{R}$ & $\mathrm{I}$ & $\mathrm{I}$ & $\mathrm{I}$ & $\mathrm{M}$ \\
\cline { 2 - 8 } & $\mathbf{4}$ & Live with & $\mathrm{R}$ & $\mathrm{I}$ & $\mathrm{I}$ & $\mathrm{I}$ & $\mathrm{M}$ \\
\cline { 2 - 8 } & $\mathbf{5}$ & Dislike & $\mathrm{R}$ & $\mathrm{R}$ & $\mathrm{R}$ & $\mathrm{R}$ & $\mathrm{Q}$ \\
\hline
\end{tabular}

Gambar 3. Matrix Kano (Walden, 1999)

Keterangan : $\quad \mathrm{M} \quad$ : Must-be

$\begin{array}{ll}\mathrm{O} & \text { : One-dimensional } \\ \mathrm{A} & \text { :Attractive } \\ \mathrm{I} & \text { : Indifference } \\ \mathrm{R} & \text { : Reverse } \\ \mathrm{Q} & \text { : Questionable result }\end{array}$

Dari matrix ini dapat diketahui apakah customer requirement tersebut termasuk pada kategori attractive, one-dimensional, must-be, indifference atau reverse. Selanjutnya adalah perekapan data untuk seluruh informasi yang diperoleh.

4. Perhitungan Customer Satisfaction Coefficient

Menurut Matzler dan Hinterhuber (1998) penentuan Customer Satisfaction Coefficient ini dilakukan untuk mengetahui pengaruh atribut terhadap produk. Berikut adalah cara menentukannya :

Nilai kepuasan (Extent to satisfaction)

$$
S_{i}=\frac{A+O}{A+O+M+I}
$$

Nilai ketidakpuasan (Extent to dissatisfaction) :

$$
S_{i}^{\prime}=\frac{O+M}{(A+O+M+I) \times(-1)}
$$

\section{METODE}

Dari topik penelitian yang ditentukan dan dari studi literatur yang telah dilakukan maka akan diperoleh perumusan masalah dan batasan penelitian. Hal ini dilakukan agar penelitian mempunyai fokus yang jelas dan hal tersebut juga yang nantinya akan menjadi acuan bagi peneliti dalam melakukan penelitian baik pengumpulan ataupun pengolahan data. Perumusan masalah ini juga mengacu pada informasi-informasi yang telah diperoleh.

Perumusan masalah yang akan dipecahkan dalam penelitian ini adalah bagaimana cara melakukan optimasi pengembangan produk dengan melakukan integrasi Model Kano pada framework 4 fase QFD dengan beberapa pendekatan konstrain pada technical response untuk mendapatkan perbandingan antara waktu dan biaya manufaktur. Dengan demikian didapatkan konsep produk yang dapat memaksimalkan kepuasan konsumen dan sekaligus sesuai dengan anggaran biaya yang dimiliki dan waktu yang dapat disediakan oleh perusahaan.

\section{A. QFD Fase 1}

Pada fase ini dilakukan pembuatan model yang mampu mengidentifikasi seberapa jauh ekspektasi pelanggan terhadap kualitas sebuah produk sepeda yang mampu memuaskan konsumen. Dalam hal ini dilakukan dengan menghubungkan antara 
Customer Requirements (CRs)/ Voice of Customer (VoC) dengan Design Requirements (DRs).

\section{Pengembangan Model Product Planning}

Model pengembangan product planning dilakukan dengan membuat perancangan model framework integrasi QFD dan Kano. Tujuannya tidak lain adalah total satisfaction of CRs dan Kano achievement levels of DRs yang dapat diperoleh.

\section{Customer Requirements}

Pada tahap ini dilakukan beberapa kegiatan di bawah ini:

a. Perekapan data tingkat kepentingan dan tingkat kepuasan dan nilai rata-rata keduanya untuk masing-masing customer requirement.

b. Perekapan data satisfaction level dan dissatisfaction level

c. Data Voice Of Customer dengan menggunakan kuisioner (kuisioner yang sudah mendapatkan validasi dari pihak yang ahli pada bidang ini).

d. Data Klasifikasi atribut berdasarkan klasifikasi teori Kano dengan menggunakan kuisioner Kano (DRs).

e. Mendapatkan data hubungan relationship antara customer requirement dan atribut/ respon teknis (hubungan antara CRs dan DRs).

f. Mendapatkan data hubungan korelasi antar atribut (korelasi antara DRs dan DRs).

g. Mendapatkan important weight fase 1

\section{Design Target Value}

Target nilai pada fase satu ini diharapkan mampu mendapatkan CRs satisfaction degree dan fullfilment level dari masing-masing DRs.

\section{B. QFD Fase 2}

Pada fase ini dilakukan pembuatan model analisis data kebutuhan material atau komponen yang mampu memenuhi kriteria design target value pada fase pertama. Dalam hal ini dilakukan dengan menerjemahkan penentuan Design Requirements (DRs) ke dalam Critical Parts Characteristics (PCs).

\section{Pengembangan Model Product Design}

Model pengembangan product design dilakukan dengan membuat perancangan model framework integrasi QFD dan Kano. Tujuannya tidak lain adalah total satisfaction of DRs dan Kano fullfilment levels of PCs yang dapat diperoleh.

\section{Design Requirements}

Pada tahap ini dilakukan beberapa kegiatan di bawah ini:

a. Data fulfillment level yang diperoleh dari design target value pada fase pertama (DRs).

b. Data klasifikasi atribut berdasarkan proses analisis pada Kano (PCs).

c. Mendapatkan data relationship antara DRs dan PCs.

d. Mendapatkan data hubungan korelasi antara PCs dan PCs.

e. Mendapatkan important weight fase 2

\section{Parts Target Values}

Pada tahap ini membuat kategori keputusan antara kebutuhan material/ komponen yang mampu disediakan oleh perusahaan terhadap faktor kompetitif desain produk yang diinginkan konsumen (DRs satisfaction degree dan fullfilment level dari masing-masing part characteristics).

\section{QFD Fase 3}

Pada fase ini dilakukan pembuatan model parameter proses yang dibutuhkan untuk memproduksi material/ komponen yang dihasilkan dari parts target value pada fase kedua. Dalam hal ini dilakukan penentuan Critical Process Parameters (PPs). 


\section{Pengembangan Model Process Planning}

Model pengembangan process planning dilakukan dengan membuat perancangan model framework integrasi QFD dan Kano. Tujuannya tidak lain adalah total satisfaction of PCs dan Kano achievement levels of PPs yang dapat diperoleh.

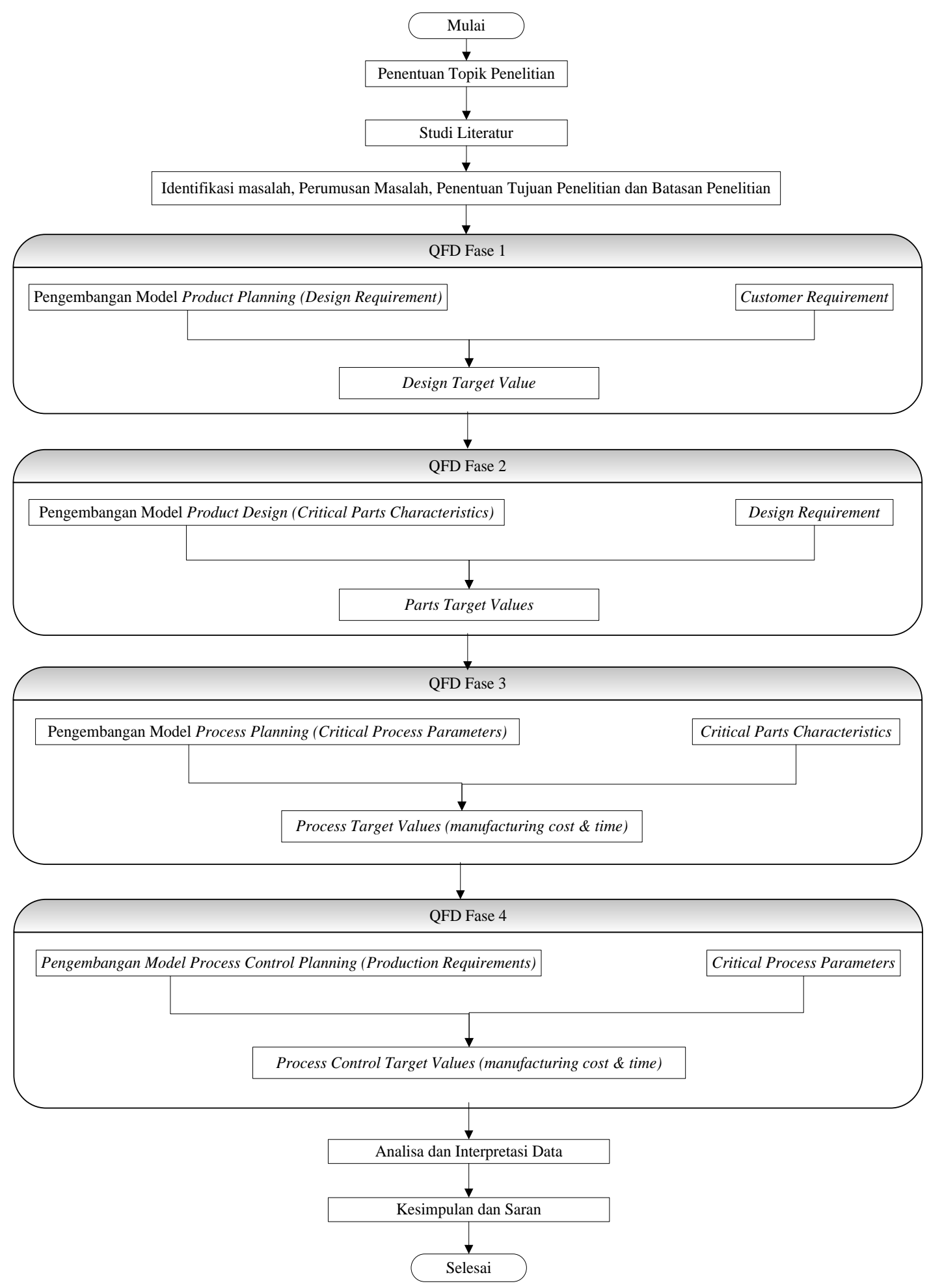

Gambar 4. Metodologi Penelitian 


\section{Critical Parts Characteristics}

Pada tahap ini dilakukan beberapa kegiatan di bawah ini:

a. Data fullfilment level dari masing-masing part characteristics yang diperoleh dari parts target value pada fase kedua (PCs).

b. Data klasifikasi atribut berdasarkan proses analisis pada QFD dan Kano (PPs).

c. Data klasifikasi time and cost operation manufacturing berdasarkan analisis Boothroyd dan Dewhurst (PPs).

d. Mendapatkan data relationship antara PCs dan PPs.

e. Mendapatkan data hubungan korelasi antara PPs dan PPs.

f. Mendapatkan impotant weight fase 3

3. Process target Values

Pada tahap ini membuat kategori keputusan antara pemilihan proses (process parameters) terhadap material/ komponen yang telah siap untuk diproses (menentukan PCs satisfaction degree dan fullfilment level dari masing-masing process parameters).

\section{QFD Fase 4}

Pada fase ini dilakukan pembuatan model urutan kebutuhan proses produksi yang dibutuhkan untuk memilih strategic manufactur decision dari critical process parameters pada fase ketiga. Dalam hal ini dilakukan pembuatan Production Requirements (PRs).

\section{Pengembangan Model Process Control Planning}

Model pengembangan process control planning dilakukan dengan membuat perancangan model framework integrasi QFD dan Kano. Tujuannya tidak lain adalah total satisfaction of PPs dan QFD dan Kano achievement levels of PRs yang dapat diperoleh.

2. Critical Process Parameters

Pada tahap ini dilakukan beberapa kegiatan di bawah ini:

a. Data fullfilment level dari masing-masing process parameters yang diperoleh dari processs target value pada fase ketiga (PPs).

b. Data klasifikasi atribut berdasarkan proses analisis pada QFD dan Kano (PRs).

c. Data klasifikasi time and cost operation manufacturing berdasarkan analisis Boothroyd dan Dewhurst (PRs).

d. Mendapatkan data relationship antara PPs dan PRs.

e. Mendapatkan data hubungan korelasi antara PRs dan PRs.

f. Mendapatkan important weight fase 4

3. Process Control Target Values

Pada tahap ini membuat kategori keputusan kebutuhan produksi terhadap proses parameter (strategic manufactur) yang telah ditentukan. Menghasilkan konsep desain yang mampu menjawab kebutuhan konsumen (menentukan PRs satisfaction degree dan fullfilment level dari masing-masing Production Requirements).

\section{ILUSTRASI}

Penelitian ini membutuhkan objek amatan jenis produk yang memiliki proses manufaktur cukup kompleks. Hal ini dilakukan karena pada proses pengembangan model integrasi 4 Fase QFD ini, peneliti akan memfokuskan pada perhitungan biaya dan waktu pada proses manufakturnya. Dengan demikian diharapkan perilaku model akan lebih tampak dengan semakin kompleksnya di bagian proses manufaktur. Produk yang dipilih sebagai objek amatan yang memenuhi beberapa kriteria tersebut adalah produk sepeda. Sepeda merupakan produk yang memiliki proses manufaktur dan sekaligus memiliki bagian-bagian part yang cukup kompleks. Oleh karena itu, produk sepeda dirasa mampu sebagai objek amatan pada pengembangan model integrasi 4 Fase QFD ini. 
Produk sepeda yang digunakan akan dipilih dari PT. XYZ. PT. XYZ merupakan salah satu produsen sepeda terkemuka di Indonesia dengan kualitas produk yang bersaing. Perusahaan ini memproduksi berbagai jenis sepeda seperti city bike, trekking, MTB (Mountain Bike), full-suspension, hard-tail bikes, downhill dan beberapa jenis sepeda lainnya. PT. XYZ ini memiliki sebanyak 155 model sepeda dan jenis produk sepeda yang dipilih sebagai objek amatan adalah city bike. Salah satu jenis city bike yang diproduksi oleh PT. XYZ yaitu city bike jenis XX. Jenis city bike dipilih sebagai objek amatan dengan pertimbangan bahwa saat ini perusahaan ingin melakukan proses pengembangan produk pada jenis sepeda tersebut dan difokuskan pada jenis XX karena adanya kemudahan dalam meng-customize sepeda ini (Yulismatun dan Singgih, 2012).

City bike merupakan jenis sepeda yang dirancang hanya untuk jarak pendek dan digunakan untuk hilir mudik pada permukaan aspal yang datar. Selain itu, jenis sepeda ini dapat digunakan untuk keperluan sehari-hari, dengan pakaian normal dan dalam segala kondisi cuaca.

City bike dapat membuat penggunanya tetap rapi saat menggunakan jenis sepeda ini. Selain itu, jenis sepeda city bike juga sering dilengkapi dengan keranjang yang dapat memudahkan pengguna ketika membawa barang. Fitur-fitur lain seperti kickstand, lampu dan carrier juga akan membantu memudahkan pengguna saat menggunakan sepeda jenis city bike tersebut.

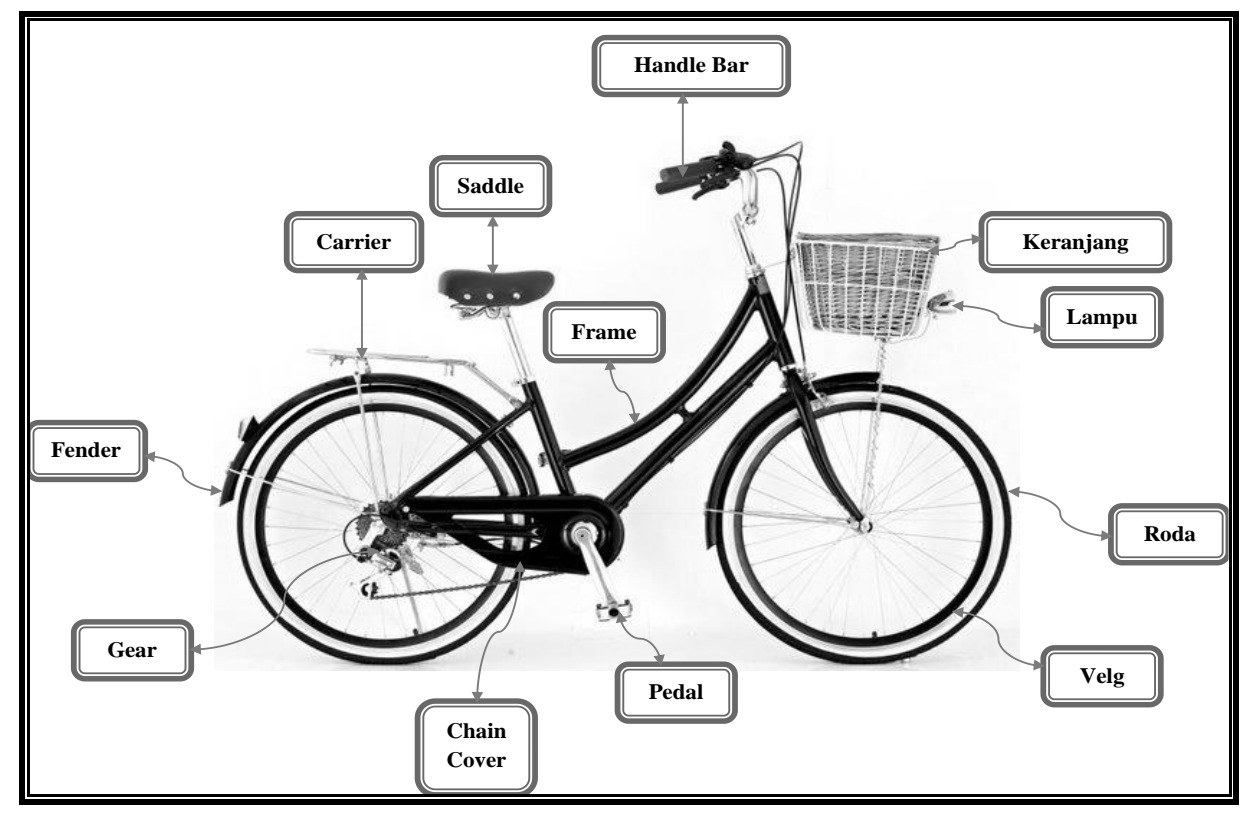

Gambar 5. City Bike dan bagian-bagiannya

Jenis sepeda city bike ini lebih dikenal di negara-negara Eropa seperti pada gambar 5 yang menunjukkan berbagai aktivitas pengguna city bike. City bike mulai banyak digunakan di Indonesia pada tahun 1970an. Namun, tidak seperti trend city bike di Eropa yang banyak digunakan oleh masyarakat perkotaan, city bike di Indonesia lebih identik dengan sepeda pedesaan dan kuno (Yulismatun dan Singgih, 2012). 


\section{HASIL DAN PEMBAHASAN}

Pada hasil akhir aplikasi Model QFD Fase 4 seperti yang terlihat dari gambar 5.1, alokasi waktu dan biaya pada ilustrasi diatas dimulai dengan perhitungan nilai technical Assembly Cost (AC) dan technical Assembly Time (AT) $\left(\left|\frac{w s_{Q j}^{\prime}}{w s_{Q j}^{\prime}}\right|\right)$. Selanjutnya akan dilakukan perhitungan Rasio AC \& AT Importance dengan rumus $w_{Q j}^{*} \times\left|\frac{w s_{Q j}}{w s_{Q j}^{\prime}}\right|$ yang rekapan hasil perhitungannya dapat dilihat pada tabel 5.1. Tabel ini menyatakan bahwa Rasio AC \& AT Importance merupakan nilai yang menunjukkan besarnya kontribusi tingkat kepentingan production requirements dengan memperhatikan nilai korelasinya. Semakin besar nilai ini, maka menunjukkan bahwa production requirements tersebut memiliki tingkat kepentingan/ kontribusi yang besar untuk mewujudkan sebuah produk sepeda.

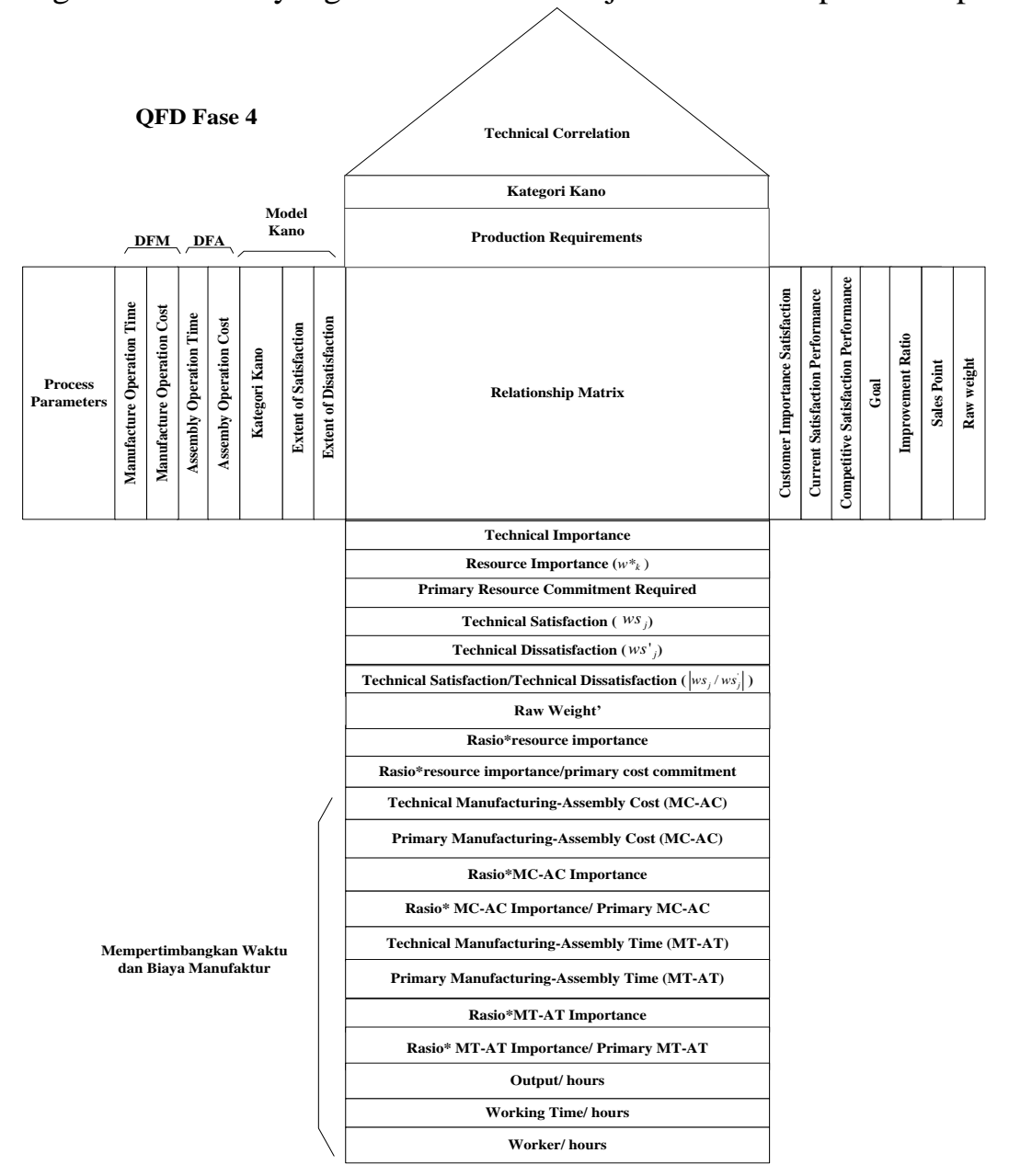

Gambar 6. Aplikasi Model QFD Fase 4

Ketika production requirements ini diwujudkan akan memungkinkan ter-cover nya production requirements yang lain. Kemampuan untuk meng-cover production requirements yang lain ini tentu akan dapat mewujudkan process parameters yang lebih baik dan banyak. Dengan terwujudnya process parameters ini, maka tentu juga akan berpengaruh pada peningkatan kepuasan konsumen. Berdasarkan analisa inilah, maka nilai Rasio*resource importance dapat dijadikan salah satu faktor untuk mengetahui nilai 
kepuasan konsumen sekaligus bobot kepentingan biaya dan waktu yang harus dialokasikan untuk mewujudkan sebuah produk sepeda. Secara lebih detil tingkat kepentingan dari masing-masing production requirements dapat diputuskan berdasarkan alokasi waktu dan biaya yang tersedia sesuai dengan kondisi PT. XYZ pada saat itu.

Tabel 1. Trade Off Nilai Bobot - antara Tingkat Kepuasan, Biaya dan Waktu

\begin{tabular}{|c|c|c|c|}
\hline PRs (Production Requirements) & $\begin{array}{c}\text { Rasio*resource } \\
\text { importance }\end{array}$ & $\begin{array}{l}\text { Rasio*MC } \\
\text { importance }\end{array}$ & $\begin{array}{l}\text { Rasio*MT } \\
\text { importnace }\end{array}$ \\
\hline $\begin{array}{l}\text { Head Tube, pipa diameter } 34 \times 2.0 \times 6 \mathrm{~m} \\
\text { Bracket She, Bottom Bracket Shell, BC: }\end{array}$ & 3.10 & 0.85 & 0.85 \\
\hline $1.37 \times 24 T$ with $\%$ hole diameter $6 \mathrm{~mm}, 1 \mathrm{H}$ & 0.01 & 0.00 & 0.00 \\
\hline $\begin{array}{l}\text { Seat Tube, pipa diameter } 1-1 / 4 \times 2.2 \times 6 \mathrm{~m} \\
\text { Seat Clamp, Seat clamp F-606, Steel Raw }\end{array}$ & 3.10 & 0.85 & 0.85 \\
\hline Finish, Diameter : $28.6 \mathrm{~mm}$ & 0.01 & 0.00 & 0.00 \\
\hline Down Tube, pipa diameter $2 \times 1.4 \times 6 \mathrm{~m}$ & 3.19 & 0.87 & 0.87 \\
\hline Top Tube, pipa diameter $5 / 8 \times 1.2 \times 6 \mathrm{~m}$ & 3.19 & 0.87 & 0.87 \\
\hline Seat Stay, pipa diameter $7 / 8 \times 1.2 \times 6 \mathrm{~m}$ & 3.10 & 0.85 & 0.85 \\
\hline $\begin{array}{l}\text { Chain Stay, pipa diameter } 7 / 8 \times 1.2 \times 6 \mathrm{~m} \\
\text { Rear End, Frame End YSA-1, Steel Raw } \\
\text { Finish, A: } 52 \text { Degree, T: } 4 \mathrm{~mm}, B: 2-\text { M6 }\end{array}$ & 3.10 & 0.85 & 0.85 \\
\hline & 0.26 & 0.02 & 0.02 \\
\hline Up Bridge, pipa diameter $5 / 8 \times 1.2 \times 6 \mathrm{~m}$ & 3.10 & 0.85 & 0.85 \\
\hline Lower Bridge, plat $2.3 \times 4 \times 8$ & 3.10 & 0.85 & 0.85 \\
\hline $\begin{array}{l}\text { Cable Guide, Cable Guide F-504, Steel } \\
\text { Raw Finish }\end{array}$ & 0.33 & 0.06 & 0.06 \\
\hline $\begin{array}{l}\text { Cable Stopper, Cable Stopper JY-506, Steel } \\
\text { Raw Finish, TBS 2008-2009 }\end{array}$ & 0.33 & 0.06 & 0.06 \\
\hline $\begin{array}{l}\text { Pivot, PivotF-101, Steel Raw Finish, Steel } \\
\text { One Piece Type, } 1 \text { set of } 2 \text { pcs }\end{array}$ & 0.33 & 0.06 & 0.06 \\
\hline $\begin{array}{l}\text { Carrier Fitting, Carrier Fitting Nut F-604, } \\
\text { Steel Raw Finish }\end{array}$ & 0.33 & 0.06 & 0.06 \\
\hline $\begin{array}{l}\text { Cable Guide, Cable Guide TC-S10, Plastic, } \\
\text { Black Color for BB Shell } 34 \times 40 \times 68 \mathrm{~m}\end{array}$ & 0.33 & 0.06 & 0.06 \\
\hline Stiker SNI 120-005-1200019 (Hologram) & 0.43 & 0.03 & 0.03 \\
\hline Paint, Steel raw Phosphate, White TC-601C & 0.46 & 0.12 & 0.12 \\
\hline Selle Royal, elastomer & 0.02 & 0.00 & 0.00 \\
\hline Padding & 0.02 & 0.00 & 0.00 \\
\hline $\begin{array}{l}\text { Reflector Bracket VT003-1, plastic, } \\
\text { diameter 22.2 - 23.0 MM }\end{array}$ & 0.01 & 0.00 & 0.00 \\
\hline $\begin{array}{l}\text { Rim Alloy } 241-3 / 8^{\prime \prime} \text { x } 36 \text { H MOD. } 6 N \text {, with } \\
\text { safety line }\end{array}$ & 0.96 & 1.15 & 1.15 \\
\hline Basket Crazy Wave 20" & 0.01 & 0.00 & 0.00 \\
\hline Deck kickstand, plat $2.5 \times 4 \times 8$ & 0.01 & 0.00 & 0.00 \\
\hline Gear transmition & 0.16 & 0.01 & 0.01 \\
\hline Safety key mode & 0.01 & 0.00 & 0.00 \\
\hline
\end{tabular}

Pada penelitian ini dilakukan integrasi antara model dasar Bode dan Fung (1998), Yulismatun dan Singgih (2012) dan modifikasi integrasi 4 Fase QFD. Pada pengembangan 
model integrasi 4 Fase QFD ini menghasilkan engineering characteristics, part characteristics, process parameters dan production requirements, dimana seluruh technical response tersebut yang masuk atau terpilih menjadi inputan proses integrasi 4 Fase QFD dapat dialokasikan dana dan waktu sebesar 100\%. Ini berarti bahwa dalam mengembangkan produk untuk memproduksi produk sepeda merupakan sebuah hubungan yang kritikal dalam urutan kejadian yang dimulai dari sebuah ide kreatif dan berakhir dengan produk yang nantinya berhasil di pasar, dan pada saat seperti sekarang ini, desain (pengembangan produk), penentuan biaya dan waktu untuk proses produksi dan sebagainya itu telah menjadi sebuah bagian yang sangat penting.

Oleh karena proses manufaktur menjadi hal yang sangat inti atau sangat penting untuk terciptanya sebuah produk., maka keberadaan manufaktur dan assembly akan sangat membantu dalam menentukan kapasitas waktu dan biaya dalam sebuah manufaktur. Manufaktur dan desain (dalam mengembangkan produk) sering kali dalam sebuah perusahaan dipisahkan menjadi dua buah unit yang berbeda. Rintangan antara desain (mengembangkan produk) dan manufaktur dapat menghalangi interaksi kedua fungsi engineering yang seharusnya saling memberi masukan.

Dari setiap proses untuk menghasilkan produk, akan selalu ada permasalahan yang timbul seiring dengan tujuan dalam mencapai tujuan tertentu (adanya trade-off antara waktu, kualitas dan biaya). Nilai trade off bobot kepetingan antara kualitas, biaya dan waktu dari produk sepeda jenis XX pada PT. XYZ ini dapat ditunjukkan pada nilai rasio* resource importance, rasio* Manufacturing Cost (MC) importance, dan rasio* Manufacturing Time (MT) importance seperti yang ditunjukkan pada Tabel 5.1. Dengan adanya trade off tersebut diharapkan dalam mendesain sebuah rancangan proses manufaktur sebuah produk sepeda dapat diproses dengan menggunakan tahapan proses yang menggunakan teknik atau kontrol tertentu sehingga dapat menjadi produk akhir yang memiliki nilai tambah yang baru.

\section{KESIMPULAN}

Pengembangan model integrasi 4 Fase QFD pada penelitian ini bertujuan untuk mendapatkan mendapatkan engineering characteristics, mendapatkan part characteristics, mendapatkan process parameters, mendapatkan production requirements, menentukan biaya dan durasi waktu yang dibutuhkan untuk mengembangkan produk dan terakhir menentukan perbandingan biaya dan waktu. Dimana pada penelitian ini, biaya dan waktu dibagi dalam dua bagian yaitu biaya dan waktu dari proses manufaktur itu sendiri yang satunya adalah waktu dan biaya dari proses assembly-nya. Berdasarkan pengembangan model dan proses implementasi yang telah dilakukan, maka akan didapatkan kesimpulan sebagai berikut :

1. Pada fase 1 didapatkan engineering characteristics, dimana engineering characteristics digunakan sebagai inputan framework integrasi QFD dan konsep Kano pada fase 1. Aplikasi teori Kano akan dijadikan sebagai dasar pengelompokan customer requirements dan technical importance sehingga dapat diketahui bagaimana pengaruh masing-masing design requirements pada tingkat kepuasan konsumen. Pada fase 2 didapatkan part characteristics, dimana part characteristics digunakan sebagai inputan framework integrasi QFD dan konsep Kano pada fase 2. Aplikasi teori Kano akan dijadikan sebagai dasar pengelompokan design requirements dan technical importance sehingga dapat diketahui bagaimana pengaruh masing-masing part characteristics pada tingkat pemenuhan design requirements. Pada fase 3 didapatkan parameter process, dimana parameter process digunakan sebagai inputan framework integrasi QFD dan konsep Kano pada fase 3. Aplikasi teori Kano akan dijadikan sebagai dasar pengelompokan part characteristics dan technical importance sehingga dapat diketahui bagiamana pengaruh masing-masing parameter process pada tingkat pemenuhan part characteristics. Pada fase 4 didapatkan production requirements, dimana production requirements digunakan sebagai inputan framework integrasi QFD dan konsep Kano pada fase 4. Aplikasi teori Kano akan dijadikan sebagai dasar pengelompokan 
parameter process dan technical importance sehingga dapat diketahui bagiamana pengaruh masing-masing production requirements pada tingkat pemenuhan parameter process.

2. Trade off antara kualitas, waktu dan biaya bisa didapatkan dari hasil pengembangan model QFD fase 4, dimana hasil hasil trade off itu adalah dari nilai technical satisfaction, nilai technical manufacturing time dan nilai technical manufacturing cost.

\section{DAFTAR PUSTAKA}

Akao, P. Y. (2011). "QFD for Product Development." Meeting Japanese Quality Management Guru Seminar on QFD for Product Development.

Almannai, B., R. G. Â, et al. (2008). "A decision support tool based on QFD and FMEA for the selection of manufacturing automation technologies." Robotics and ComputerIntegrated Manufacturing 24: 501-507.

Andreasen, M.M., Kahler, S., and Lund, T. (1983)."Design For Assembly. " Berlin, Heidelberg, Newyork, Tokyo, IFS Ltd, U.K.

Benner, M. (2003). "Quality Function Deployment (QFD)." Food Quality and Preference 10(4): 377-339.

Bode, J. and R. Y. K. Fung (1998). "Cost Engineering with Quality Function Deployment The Need For Cost Considerations in Quality Illustrated Example." 35: 587-590.

Boothroyd., G., Dewhurst, P., and Knight, W (1985). "Product Design for Assembly." New York, Boothroyd Dewhurst, Inc.

Boothroyd, G., Dewhurst, P., and Knight, W., (1994) "Product Design for Manufacture and Assembly." New York, Marcel Dekker, Inc, 1994.

Bottani, E. (2009). "A fuzzy QFD approach to achieve agility." International Journal of Production Economics 119(2): 380-391.

Centre, E. D. and N. Square (1995). "Design function deployment- a design system for the future." 16: 447-470.

Chang, Y.-C., C.-T. Liu, et al. (2009). "Optimization of process parameters using weighted convex loss functions." European Journal Of Operational Research 196(2): 752763.

Chen, C.-H. and M. B. C. Khoo (2009). "Optimum process mean and manufacturing quantity settings for serial production system under the quality loss and rectifying inspection plan." Computers \& Industrial Engineering 57(3): 1080-1088.

Chen, C.-H. and M.-T. Lai (2007). "Determining the optimum process mean based on quadratic quality loss function and rectifying inspection plan." European Journal Of Operational Research 182(2): 755-763.

Chen, L.-h. and W.-c. Ko (2009). "Fuzzy linear programming models for new product design using QFD with FMEA." Applied Mathematical Modelling 33(2): 633-647.

Chen, L.-H. and W.-C. Ko (2010). "Fuzzy linear programming models for NPD using a four-phase QFD activity process based on the means-end chain concept." European Journal Of Operational Research 201(2): 619-632.

Chen, L.-H. and M.-C. Weng (2003). "A fuzzy model for exploiting quality function deployment." Mathematical and Computer Modelling 38(5-6): 559-570.

Chen, Y.-T. and T.-Y. Chou (2011). "Applying GRA and QFD to Improve Library Service Quality." The Journal of Academic Librarianship 37(3): 237-245.

Cheng, B.-w. and N. Yunlin (1995). "Optimization of Mechanical Assembly Tolerances by Incorporating Taguchi ' s Quality Loss Function." 14(4): 264-276.

Cristiano, J. J., J. K. Liker, et al. (2001). "Key factors in the successful application of quality function deployment (QFD)." IEEE Transactions on Engineering Management 48(1): 81-95.

Cohen, L. (1995), ). "Quality Function Deployment" Addison-Wesley Publishing Company. 
Crow, K,. (2007) "Design For Manufacturability/Assembly Guidelines. " http://www.npdsolutions.com/dfmguidelines.html

Delgado, D. J. and E. M. Aspinwall (1995). "QFD Methodology and Practical Applications - A Review Figure 1. The House of Quality." 1: 1-5.

Delgado-Hernandez, D. J., K. E. Bampton, et al. (2007). "Quality function deployment in construction." Construction Management and Economics 25(6): 597-609.

Delice, E. K. and Z. Güngör (2009). "A new mixed integer linear programming model for product development using quality function deployment." Computers \& Industrial Engineering 57(3): 906-912.

Elsevier, I. F. (1997). "Kansei engineering research on the design of construction machinery." 19: 129-146.

Freiesleben, J. (2008). "A proposal for an economic quality loss function." International Journal of Production Economics 113(2): 1012-1024.

Garibay, C., Gutiérrez, H. \& Figueroa, A. (2010). "Evaluation of A Digital Library by Means of Quality Function Deployment (QFD) and The Kano Model". The Journal of Academic Librarianship, 36, 125-132.

Govers, C. P. M. (1996). "production What and how about quality function deployment ( QFD )." 47(95): 575-585.

Hassan, A. and I. Dayarian (2008). "Cost-based FMEA and ABC Concepts for Manufacturing Process Plan Evaluation." Event (London): 197-202.

Hassan, A., A. Siadat, et al. (2010). "Robotics and Computer-Integrated Manufacturing Conceptual process planning - an improvement approach using QFD , FMEA , and ABC methods." Robotics and Computer Integrated Manufacturing 26(4): 392-401.

Jia, G. Z. and M. Bai (2011). "Computers \& Industrial Engineering An approach for manufacturing strategy development based on fuzzy-QFD." Computers \& Industrial Engineering 60(3): 445-454.

Karl T, Ulrich., and Steven, D., Eppinger., "Product Design and Development. "

K1lıç, E. and Z. Güngör (2009). "Computers \& Industrial Engineering A new mixed integer linear programming model for product development using quality function deployment." Computers \& Industrial Engineering 57(3): 906-912.

Kulkarni, S. S. (2008). "Loss-based quality costs and inventory planning: General models and insights." European Journal Of Operational Research 188(2): 428-449.

Kumar, A., J. Antony, et al. (2006). "Integrating quality function deployment and benchmarking to achieve greater profitability." Benchmarking: An International Journal 13(3): 290-310.

Kotler, P. (2002 ). "Manajemen Pemasaran." Salemba Empat Andi, Yogyakarta.

Kwong and M. Bai. (2001). "A fuzzy AHP approach to the determination of importance weight of customer requirements in quality function deployment." European Journal Of Operational Research 188(2): 428-449.

Lai, X., M. Xie, et al. (2008). "Ranking of customer requirements in a competitive environment." Computers \& Industrial Engineering 54(2): 202-214.

Lee, Y.-c., L.-c. Sheu, et al. (2008). "Quality function deployment implementation based on Fuzzy Kano model : An application in PLM system." Quality 55: 48-63.

Lin, S. P., Yang, C. L., Chan, Y.-H. \& Sheu, C. (2010). "Refining Kano's 'Quality Attributes-Satisfaction' Model: A".

Liu, H.-t. (2009). "Expert Systems with Applications The extension of fuzzy QFD : From product planning to part deployment." Expert Systems with Applications 36(8): 11131-11144.

Luo, Z. J. and D. Liu (1995). "Evaluation of IN718 disk-forging processes using the qualityloss function." 0136(95): 381-385.

Matzler, K. \& Hinterhuber, H. H. (1998). "How to Make Product Development Projects more Succesful by Integrating Kano's Model of Customer Satisfaction into Quality Function Deploymen"t. Technovation, 18, 25-38. 
Matzler, K., Hinterhuber, H. H., Bailom, F. \& Sauerwein, E. (1996). "How To Delight Your Customers". Journal Of Product \& Brand Management, 5, 6-18.

Min, D.-k. and K.-j. Kim (2008). "An extended QFD planning model for selecting design requirements with longitudinal effect consideration." Expert Systems with Applications 35: 1546-1554.

More, K. and D. Ingman (2008). "Quality approach for multi-parametric data fusion." NDT \& E International 41(3): 155-162.

Nagamachi, M. (2002). "Kansei engineering as a powerful consumer-oriented technology for product development." Applied ergonomics 33(3): 289-294.

Ozdemir, G. and I. Engineering (2004). "Quadratic Quality Loss Functions and Signal-toNoise Ratios for a Trivariate Response." 23(2).

Prasad, B., E. Data, et al. (1998). "Review of QFD and Related Deployment Techniques." (3): 221-234.

Sauerwein, E., Bailom, F., Matzler, K., and Hinterhuber, H. H. (1996). "The Kano Model: How to Delight Your Customer". Production, I(9), 313-327

Schütte, S. and J. Eklund (2005). "Design of rocker switches for work-vehicles--an application of Kansei Engineering." Applied ergonomics 36(5): 557-567.

Suef, M. (2012). "Isu Penting Dalam perkembangan Metode QFD Sebagai Alat Bantu Perancangan Produk."

Walden, D. center of Q. M. (1999). "Kano's Methods for Understanding Customer-defined Quality", The Center for Quality of Management, Inc.2(4), 1-37.

Wang, H. and A. Z. Lin (2008). "Defects tracking matrix for mass customization production based on house of quality." Quality(2007): 666-684.

Wu, C.-C., Z. Chen, et al. (1998). "Component tolerance design for minimum quality loss and manufacturing cost." Computers in Industry 35(3): 223-232.

Wu, F.-c. and I. Management (2004). "Optimization of Correlated Multiple Quality Characteristics Robust Design Using Principal Component Analysis." 23(2).

Xu, Q., R. J. Jiao, et al. (2009). "An analytical Kano model for customer need analysis." Design Studies 30(1): 87-110.

Yulismatun, F. and M. L. Singgih (2012). "Pengembangan Model Integrasi Kano-QFD Untuk Optimasi Kepuasan Konsumen."

Zhai, L. Y., L. P. Khoo, et al. (2010). "Expert Systems with Applications Towards a QFDbased expert system : A novel extension to fuzzy QFD methodology using rough set theory." Expert Systems with Applications 37(12): 8888-8896.

Zhai, L.-Y., L.-P. Khoo, et al. (2009). "A rough set based QFD approach to the management of imprecise design information in product development." Advanced Engineering Informatics 23(2): 222-228 
